\title{
Study on the Application of Cognitive Apprenticeship in English Audio-visual Teaching in Colleges and Universities
}

\author{
Yi Zhang, Jun Zhao \\ Rongcheng College, Harbin University of Science and Technology, Rongcheng Shandong, 264300, \\ China
}

Keywords: English Teaching in Colleges and Universities, Audio-visual Teaching, Cognitive Apprenticeship, Application

\begin{abstract}
English audio-visual teaching uses multimedia to assist teaching, and creates English learning space in classroom teaching. With sufficient communication between teachers and students, English teachers guide students to change traditional learning modes, take an active part in independent learning behavior, learn English knowledge in an exploring way, and form English cognition. English teaching in colleges and universities introduces cognitive apprenticeship to teaching environment, and carries out English quality-oriented education in accordance with students' knowledge demand and development characteristics in order to improve the efficiency of English audio-visual teaching. This paper focuses on the application of cognitive apprenticeship in English audio-visual teaching in colleges and universities.
\end{abstract}

\section{Introduction}

College English audio-visual teaching uses multimedia to assist English teaching in the process of college English classroom teaching so that students' visual feeling of English teaching contents in English class can be generated and their emotion can be stimulated to motivate their passion for English learning, which is useful for not only the improvement of students' English performance but also the cultivation of students' English learning ability. As for higher education, the essence is to facilitate students' integrated development and the emphasis is to improve learning ability in order to cultivate students' lifelong learning habit. Introducing cognitive apprenticeship to college English audio-visual teaching can improve college students' English cognitive competence and achieve better English teaching effects.

\section{Understanding of cognitive apprenticeship}

In the late 1980s, various disadvantages of traditional education mode in Chinese colleges and universities appeared, seriously affecting the quality of teaching. Especially in teaching process, teachers still focused on classroom teaching and knowledge transmission, lacking consideration of cultivating students' knowledge cognitive ability. Although college students learn the knowledge and grasp the knowledge taught by teachers, they still lack the ability of knowledge application. As a result, theoretical knowledge and application knowledge are not integrated together substantially, which is adverse to the practical ability cultivation of talents in colleges and universities. In 1989, two famous American cognitive science researchers respectively named Allan Collies and John Seely Brown acquired inspiration from traditional manual apprenticeship and put forward cognitive apprenticeship in combination with the talent cultivation situations of colleges and universities at that moment. It mainly contains the contents of three aspects.

\section{Basic theory of cognitive apprenticeship}

Current education in colleges and universities mainly focuses on quality-oriented education. Top-level talents are sufficient in China, so Ministry of Education advocates that colleges and universities should change traditional education mode and pay more attention to the cultivation of college students' comprehensive quality. Quality-oriented education means fully understanding people's development rule and characteristics and facilitating people's integrated development in 
form of educational activities. Application of quality-oriented education in colleges and universities needs to analyze students' cognitive structure. If students' cognitive structure can be changed after reception of stimuli, this process of changing is called" adaptation". If students can make use of the accepted stimuli and integrate it with their own cognitive structure, the process of changing is called" assimilation" [1]. Teachers should carry out teaching in accordance with students' learning rules, making sure that students in learning process are able to abandon "adaptation "andcreate" assimilation" effect, and avoiding passive reception of the accepted knowledge information.

\section{Metaphor theory of cognitive apprenticeship}

In order to adapt to the social environment, human beings' brain is constantly evolving in lengthy society historical development. Consequently, human beings are developed to be the higher beings, their brain is fully developed to enable human beings to possess wisdom, and potential learning ability finally comes into being. Human beings' wisdom enables them to absorb knowledge and flexibly use it in accordance with their needs. With the constant improvement of cognitive neuroscience, researches progress of cerebral neuroscience is quickened constantly and applied to educational researches. As is shown in the results, human beings' learning ability is potential, and this kind of potential will be motivated because of the external stimuli and be developed as needed. It indicates that learning is a continual process. Only with learning ability can the knowledge be positively explored and can the independent study habit be formed.

\section{Situated cognition theory of cognitive apprenticeship}

Colleges and universities must respect students' dominant position in order to carry out quality-oriented education for college students. Only with harmonious and equal communication between teachers and students can students' exploration desire for knowledge be motivated and can students study independently. In process of students' independent study, knowledge hierarchy must be constructed to effectively acquire knowledge and deepen the understanding of knowledge which is exactly the core of constructivism theory. Students as the main body in college and university education integrate the acquired knowledge with grasped knowledge, process the knowledge and construct new knowledge hierarchy [2]. At that moment, students actively and selectively rather than passively receive knowledge, and integrate all the knowledge they have grasped. In the process of students' acquiring knowledge, teachers take charge of creating classroom situation suitable for students' personality characteristics, stimulating students' learning interest, and enabling students to take an active part in leaning.

\section{Introduction mode of cognitive apprenticeship in English audio-visual teaching of colleges and universities}

\section{Multimedia demonstration introduction mode of English audio-visual teaching in colleges and universities}

In order to actively take part in learning, students should be able to set up learning motivation under the stimulation of external factors. As students' subjective initiative is stimulated, they will be willing to participate in learning activities, which not only improves the learning efficiency but also expands the knowledge fields. In college English audio-visual classroom teaching, teachers should create teaching situations suitable for students' temperament and interest in order to make students interested in the classroom teaching contents. With the infection of classroom situations, students unconsciously absorb English knowledge and have correct understanding of English knowledge. In order to make students concentrate on the learning activities in classroom, English teachers can ask students to share with others some interesting things around them, raise some questions, and require students to find answers in their life. The purpose of raising questions is not asking students to give correct answers, so no fixed answers need to be set. All the appropriate answers can be considered correct. Some students share interesting stories and other students concentrate their attention on the stories, which greatly arouses students' passion for classroom situations. If it is permitted, English 
teachers can record a video of the process of students' discussing and answering questions and then play it with multimedia. In the playing process, English teachers should affirm students' expression, point out their improper behaviors, and also put forward what is correct. After seeing their own representation and comparing teachers' evaluation, students will constrain their own behavior in accordance with teachers' guidance.

Knowledge is interconnected rather than isolated. In order to make students understand this characteristic of knowledge, teachers can make students think about what knowledge of other disciplines is connected with the contents of this class. Students' thinking process is actually a process of integrating all kinds of knowledge. Only in this way can the application of English knowledge be comprehended by analogy.

Students all take an active part in teaching activities of English audio-visual classroom teaching, but due to the students' learning motivation, the teaching forms which needs to be adopted and teaching efficiency which is going to be achieved are quite different. As for students who lack self-regulation of learning, teachers can raise questions about the teaching contents, guide students to search information of all aspects, provide proper enlightenment, and enable students to successfully answer questions ${ }^{[3]}$. Along with students' enhanced confidence in English learning, their interest in English learning will also be improved, and they will carry out independent learning out of their interest. As for students with relatively higher independent learning ability, teachers should adopt incentive methods, affirm their self-regulation of learning, and make them confident in their own learning. When students' learning methods are praised by teachers, they will stick to the learning methods, and conduct constant adjustment and improvement of their independent learning methods in accordance with their own needs.

In English audio-visual teaching classroom, students actively think about questions, have full understanding of audio-visual phenomenon, and grasp certain English audio-visual knowledge at the same time. Students learn and understand new English knowledge on basis of their grasped English knowledge, which cultivates students' problem exploration ability and also improves students' language competence as well as mutual cooperation ability. Cognitive apprenticeship teaching mode takes multimedia technology as main carrier and displays the English audio-visual situations.

\section{Situation introduction cognitive mode of English audio-visual teaching in colleges and universities}

In the process of students' English learning, English teachers should explain English audio-visual knowledge and pay attention to the changes of culture block at the same time in order to practically achieve favorable learning effects and encourage students to learn English cultural knowledge related to the English classroom contents. According to students' interest in English knowledge, the English teaching activities should be designed. For example, when teaching "Shapes" Part A, teachers usually adopt the teaching approach assisted by multimedia and raise questions like"Who can tell me? What shape is the sun?" through the operation of multimedia courseware. When teachers raise this question, the pictures which take the sun as main contents can be presented. Students will correctly say "circle" after receiving teachers' hint. Afterwards, teachers will continue to ask "What shape is the rising sun?"'Rising" is a unfamiliar word for students, so in order to make students understand the connotation of this word deeply, English teachers can stimulate students' imagination in way of action language and make them understand the word. On basis of teachers' guidance and students' speculation of common sense, students can correctly answer the connotation of this word. It can be seen that compared with multimedia courseware assisted teaching, the approach of object teaching is more attractive for students. Students will have more intuitionistic feeling of English knowledge and generate deeper impression of English knowledge they have learned.

\section{Evaluation and feedback mode of English audio-visual teaching in colleges and universities}

Only by devoting to independent study, make pointed references, and absorbing knowledge in accordance with their own knowledge structure, can students achieve better learning effects. Therefore, every student at college stage will construct independent study model. Two variables in the model are respectively evaluation and feedback which are closely linked with students' English 
learning interest and learning effects. Evaluation refers to the English teachers' evaluation of students' learning effects; feedback refers to the measurement of students' English learning process situations and English learning achievement, which is taken as the main standard of evaluating English teaching quality. Evaluation and feedback supplement each other. According to the evaluation of students' English learning conditions, teachers can praise or award the students and point out students' deficiencies in English learning in way of criticism [4].

As for the design of each teaching link, English teachers must properly design the teaching contents in accordance with teaching objectives, making students actively cooperate English teachers and accomplish classroom teaching tasks. At the same time, teachers will make objective evaluation of students and receive feedback information. English teachers will play their role of classroom organizers, manage students' classroom learning, enable students to accomplish learning tasks in line with English teachers' guidance, and improve learning quality.

\section{Suspense introduction cognitive mode of English audio-visual teaching in colleges and universities}

It can be seen from cultural perspective that the cultural differences between the east and the west are obvious. College students not only take English as communicative tools but also experience English language culture through learning English. The cultural environment for students' growth will exert influences on their understanding of objects and will be reflected in learning performance. Therefore, individuals in various cultural environments will have different English learning effects, because students' self-control ability of learning behavior is different which will to a certain degree affect the independent study effects [5]. For example, education in western countries encourages students to be confident enough to independently solve all kinds of problems. Students who grow up in such social environment will inevitably have strong self-control ability and adjust their learning approaches in accordance with their own needs. Education in Asian countries focuses on passive education and students have relatively strong dependence on teachers. As for students, teachers have certain authority and students need to follow what teachers have required. Culture shows diversification in recent years which has made the English teaching in colleges and universities break traditional teaching mode and adopt flexible and diverse teaching mode. However, Chinese traditional national culture comes down in one continuous line. It will take a long time to change the traditional teaching mode thoroughly. Therefore, teachers can teach by personal example as well as verbal instruction, set a good example for students by carrying out independent study, and let students follow the good examples, which will exert certain guiding effects on students' independent study.

\section{Conclusion}

In conclusion, colleges and universities as the talents training bases pay more attention to the cultivation of college students' comprehensive quality. The main objectives of college English teaching are no longer confined to the development of students' English level but the improvement of students' English quality, which sets solid foundation for students' integrated development. In college English audio-visual teaching process, English teachers must have sufficient interaction with students, make visualized description of students' unknown words with action language, create active classroom atmosphere, and improve students' English learning effects.

\section{References}

[1] Guo Yan. Analysis on higher vocational education practical teaching mode in perspective of cognitive apprenticeship. Course Education Research,2014(08):241-242.

[2] Cao Jun. On writing workshop writing teaching mode in perspective of cognitive apprenticeship. Journal of Binzhou University, 2013(01):121-124.

[3] Zhu Dianyong, Cui Dan. Study on English audio-visual teaching leading based on cognitive apprenticeship. Heilongjiang Researches on Higher Education,2013, 31(05):186-188. 
[4] Zhang Fuhui, Zou Lidan, Dai Lihong. Study on the application mode of cognitive apprenticeship in online English mutual evaluation. Journal of Distance Education,2012(05):108-112.

[5] Yang Zhizhen. Application study of"cognitive apprenticeship" in blended teaching. Software Guide: Educational Technology, 2011,10(03):11-13. 